Vol.01/ No. 01

Pages: $38-47$

https://www.irojournals.com/itdw/

DOI: https://doi.org/10.36548/jitdw.2019.1.005

\title{
AUTOMATION USING IOT IN GREENHOUSE ENVIRONMENT
}

\author{
Dr. Jennifer S. Raj, \\ Professor, \\ Department of Electronics \& Communication Engineering, \\ Gnanamani College of Technology, Namakal, India. \\ Email: jennifer.raj@gmail.com

\section{J. Vijitha Ananthi,} \\ Research Analyst, EJesra, India. \\ Email: vijithaananthi@gmail.com
}

\begin{abstract}
Green house is generally a building of small or large structures. The structure of the green house is made of walls and the translucent roof, with the capability of maintaining the planned climatic condition. It ensures the growth of plants that requires a specified level of soil moisture, sunlight, humidity and temperature. The green house systems available are human monitored systems that entail the continuous human visit causing distress to the worker and also decrease in the yield if the temperature and the humidity are not properly and regularly maintained. This paves way for the concept of the green house automation. The green house automation formed by the incorporation of the Internet of things and the embedded system addresses the problem faced in the green house and provides with the automated controlling and monitoring of the green house environment replacing the undeviating administration of the farmers. This paper also proposes the automation using internet of things in green house environment by using the Netduino 3 and employing the sensors for the sensing the moisture, temperature, sunlight and humidity, to enhance the production rate and minimize the discomfort caused to the farmers.
\end{abstract}

Keywords: Green House, Automation, Internet of Things, Netduino 3, Atmospheric sensors

\section{INTRODUCTION}

Due to the unexpected climatic changes that occur due to the global warming, human causes and many other natural causes such as the earth tilt, ocean currents etc. Growth of the seasonal crops such as the millets, beans, cotton and sugar cane gets affected causing a decrease in the production rate of those crops. So in order to maintain a proper climatic condition by perfectly controlling the temperature humidity, soil moisture and the luminous entailed by the crops the green house is preferred in most places.

Green house structured with transparent sheets all over maintains perfect climatic conditions under the human monitoring. It requires a constant and periodic human monitoring to control the temperature, light intensity, soil moisture and the humidity to retain the required climatic condition that is entailed for the crop growth. It serves as protection against the climatic changes to extend the season for the growing the crops. 
Journal of Information Technology and Digital World (2019)

Vol.01/ No. 01

Pages: $38-47$

https://www.irojournals.com/itdw/

DOI: https://doi.org/10.36548/jitdw.2019.1.005

Despite the green house being very beneficial for the farmers as it increase the yield of the crops and production rate; it causes a discomfort for the farmers as they have to keep a periodic check on the green house by making regular visits and failure to maintain the perfect climatic conditions will result in the destruction of the crops and the production rate. The fig. 1 below shows the general green-house for growing crops under human surveillance.

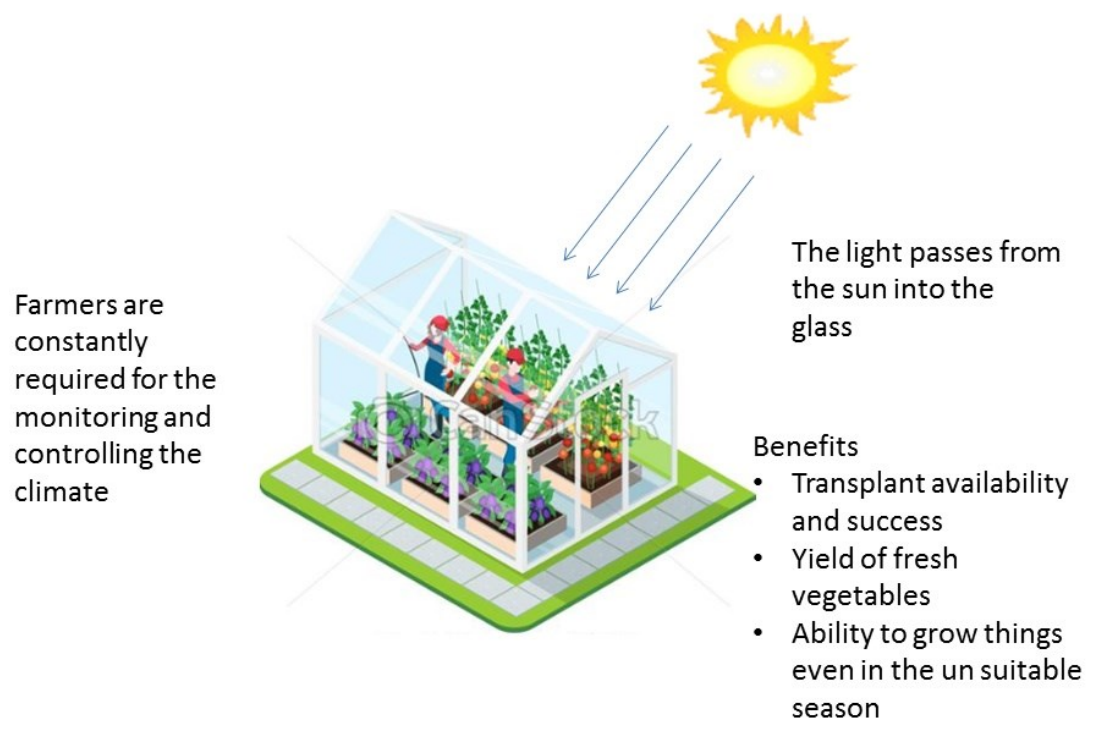

Fig.1 Structure of Green House

But the emergence of the sensors and the internet of things have changed the situation of the green-house. It has bought in the automation into the controlling and the surveillance of green-house by employing the sensors, internet of things and the embedded technology.

The paper puts forward the structure of the green house embedded with the internet of things, sensors and the Netduino $3 \mathrm{Wi}$-Fi to enable an automated monitoring and controlling in the green house.

The remaining of the paper is organized with the related works in the section 2. Proposed work in section 3, Results and Discussion in section. 4. and conclusion in section 5.

\section{RELATED WORKS}

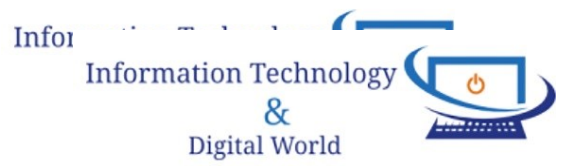


Journal of Information Technology and Digital World (2019)

Vol.01/ No. 01

Pages: $38-47$

https://www.irojournals.com/itdw/

DOI: https://doi.org/10.36548/jitdw.2019.1.005

The Internet of things have become the hear $t$ and soul for a wide range of applications by enabling a connectivity between the all the tangible things that are enabled with internet connection. The author Sreekantha et al [1], presents the literature survey on the internet of things for the online crop monitoring. He describes that the IOT enables an effective and an easy production of the crop, increasing the profits of the farmers. The Sensors also play a vital role in the monitoring of the crop growth by gathering information about the growth and sending them to the farmer's mobile devices for implementing the corrective measures. Suma, et al [2] the author strives to enhance the interest towards the agriculture by proposing an IOT based smart agriculture by providing a "remote control monitoring for sensing of the moisture, temperature, intruder, security and the leaf wetness using the GPS module" Yoon et al [3] the paper is about the farm system that is made smart by employing the low power blue tooth and communication module of low power wide area network. The controlling and the monitoring functions for the farm system is done by employing the MQ telemetry Transport" causing a progress in the agricultural IOT development. Vatari, et al [4], the author initiates a green-house environment combining the IOT and the Cloud, to control the system and enable the information to be stored respectively. Linlin et al [5], the implementation of the intelligent green-house environment is developed by the author using the internet of things, sensor and the infrared cameras Vimal et al [6], the author utilizes the Arduino based frame work for the automated controlling and the monitoring of the environmental changes in a green-house Ferrández et al [7], paves way for a ubiquitous monitoring of Zhao et al [8], the author formulates the study on the "IOT, control networks and the information networks and the integration" in order to proffer remote monitoring for the agriculture using the internet and the wireless communication. Muthupavithran et al [9], proposes the monitoring of the green-house using the internet of things. Mekala et al [10], presents the survey on the smart agriculture using the internet of things. Shukla et al [11], the author use the "microcontroller board, IOT and the Cloud server to develop an intelligent green-house to control as well as monitor the cloud. Talavera et al [12] the systematic literature review on the application of the internet of things in the agricultural industry and the environment is discussed in the paper along with the report of the preparation, conveyance and the outcomes.

\section{PROPOSED WORK}

To overcome the draw backs in the existing system, the proffered system uses the sensors to monitor the temperature, humidity, moisture and the light, the sensors are connected to the input pins of the Netduino and the output from the Netduino is given to the motors and the relays to regulate the flow of the climatic condition. Based on the threshold value set for the temperature, moisture, humidity and the light the Netduino operates the driver circuit to regulate the flow of the of the air and the temperature. The Wi-Fi connectivity in the Cloud enables to transmit the information gathered from the sensors to the cloud and gets stored in the cloud data base. The information stored in the cloud is regularly transmitted to the farmer's mobile device over the internet to initiate a remote monitoring. This enables to elude the human to machine interaction and provides a machine to machine interaction.

Infor Information Technology \& Digital World 
Vol.01/ No. 01

Pages: $38-47$

https://www.irojournals.com/itdw/

DOI: https://doi.org/10.36548/jitdw.2019.1.005

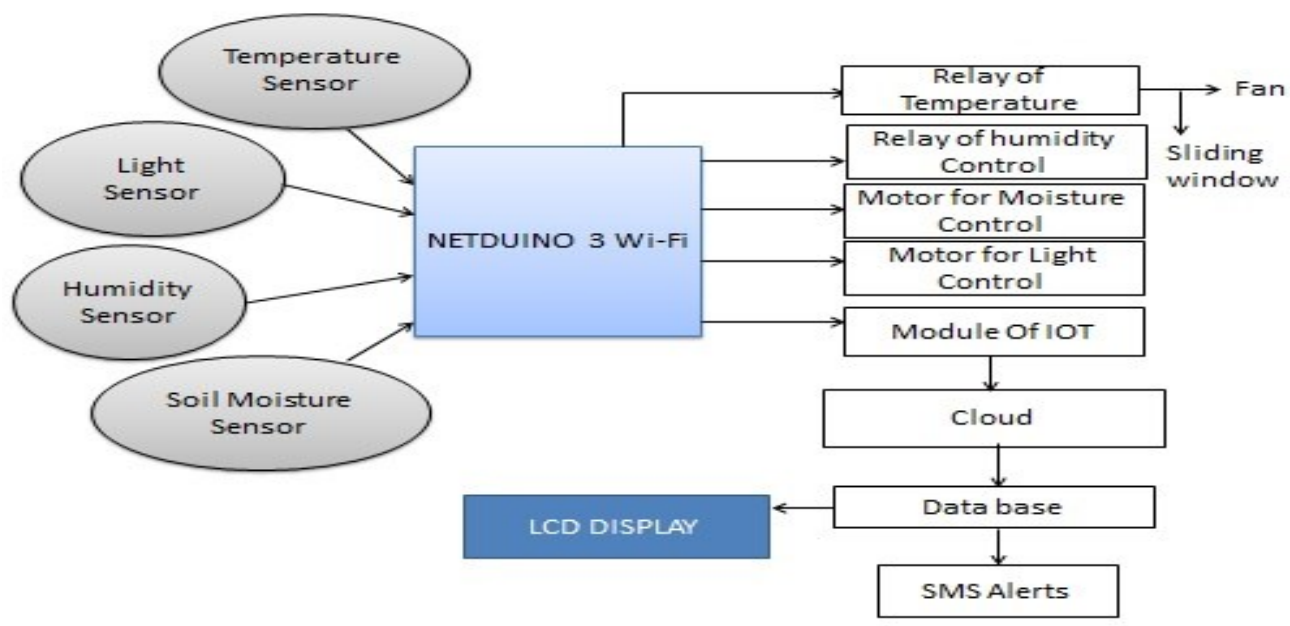

Fig .2 Proposed Structure

The proffered internet of things platform provides an automated form of green- house environment enabling a significant connections among the people and the tangible things around, it allows a real time information gathering, analysis, processing and meditation employing the social networking that are connected through an application interface that is open source to aid variety of platforms. The system put forward for providing the automated controlling and monitoring gathers and conveys the sensor information using the Google cloud IOT core, to have an anywhere and a anytime access of the information that are sensed in the green house, this would enable production rate increase and be beneficial for the farmers reducing the weariness in them.

\subsection{HARDWARE USED}

\subsubsection{NETDUINO 3 Wi-Fi}

The Netduino is open source hardware, and ensures the execution of the application that was constructed with the Dot Net frame work. The Netduino is capable of and are utilized in constructing any connected thing. It resembles the conception of the Arduino. The Netduino is more effective and provides a robust hardware. The Netduino is the vital core of our this project, it is a single board, built with the Cortex-M4 @168Mhz, flash memory of 1408 KB, RAM of 
Journal of Information Technology and Digital World (2019)

Vol.01/ No. 01

Pages: $38-47$

https://www.irojournals.com/itdw/

DOI: https://doi.org/10.36548/jitdw.2019.1.005

164+ KB , inbuilt Wi-Fi, Bluetooth connectivity and has network connectivity with $802.11 \mathrm{~b} / \mathrm{g} / \mathrm{n}$ with SSL /TLS 1.2 support. It is powered with the built in USB adapter and accepts input voltage of $5 \mathrm{~V}$ to $12 \mathrm{~V}$. The steps to run the Netduino initiates with the installation of the Netduino on the SD card Slot, the python programming is done on the windows platform. The programming of the Netduino and the application programming are run simultaneously using the XMING .

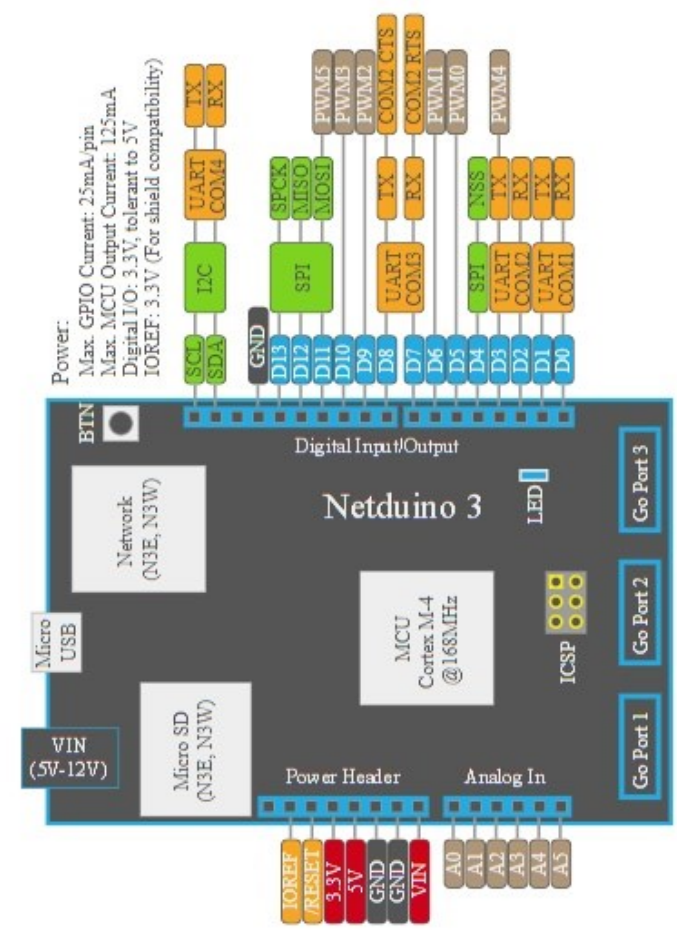

Fig .3 Netduino $3 \mathrm{Wi}-\mathrm{Fi}$

\subsubsection{Soil moisture sensor}

The automated system utilizes the YL69 moisture sensor to sense the moisture in the soil. The soils moisture sensor is powered by the operating voltage of $3.3 \mathrm{v}$ to $5 \mathrm{v}$ and current of $35 \mathrm{~mA}$. The tow electrodes found in the moisturizer are placed in contact with the soil. Initially when it is placed into the soil the voltage fluctuates, an increase in the voltage is found if the soil moisture is less and voltage decrease with the increase in the soil moisture. $[4,5,6,9]$ 
Journal of Information Technology and Digital World (2019)

Vol.01/ No. 01

Pages: $38-47$

https://www.irojournals.com/itdw/

DOI: https://doi.org/10.36548/jitdw.2019.1.005

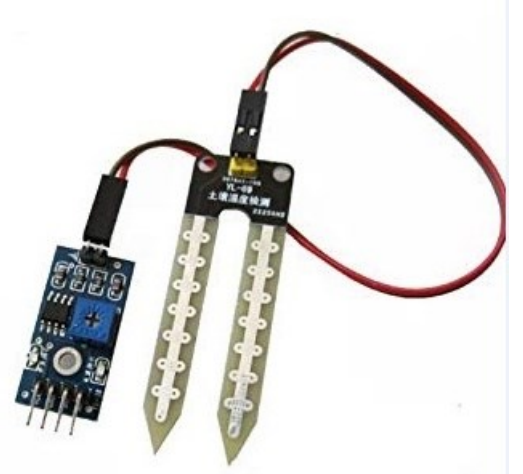

Fig. 4 Moisture Sensor

\subsubsection{Humidity and temperature sensor}

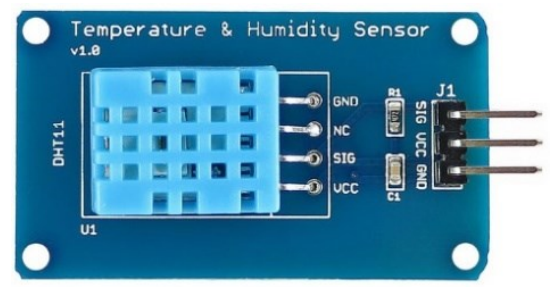

Fig.5 Temperature and Humidity Sensor (DTH11)

It is a digital sensor to monitor and gather information about the temperature and humidity that is prevailing in the green house. It is operated in the voltages of the 3 to 5 volts with the maximum current of $2.5 \mathrm{~mA}$. Range for the temperature is fixed to zero degree to fifty degree and the humidity percentage is set in between 20 to 80 percentages. The thermistor present inside engages a negative temperature coefficient and component to sense the humidity to identify the moisture content in the air.

\subsubsection{Light sensor}

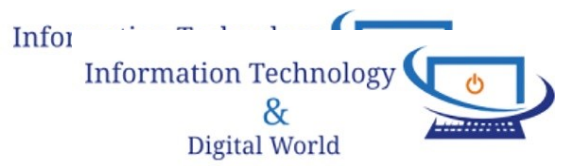


Journal of Information Technology and Digital World (2019)

Vol.01/ No. 01

Pages: $38-47$

https://www.irojournals.com/itdw/

DOI: https://doi.org/10.36548/jitdw.2019.1.005

This enables an incorporated control of the green house environments; GL5528 detects the light intensity of the environment. It is powered by the input voltage of $5 \mathrm{~V}$. The output voltage of the light sensor changes based on the light intensity whenever the light intensity increases the voltages sensed at the output is very high and when the intensity of the light decreases the output voltage decreases.

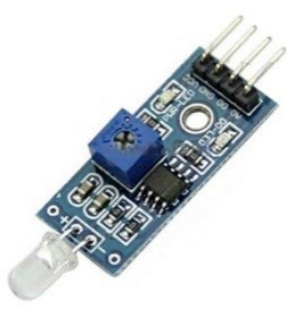

Fig.6 Light Sensor

Along with the sensors the motor driver circuit IC L293D along with the coolers and the sliding windows are set to assist the motor to run and retain the temperature for regulating the air flow within the green house.

\section{Results and Discussion}

The hard ware setup of the proffered system consisting of the Netduino $3 \mathrm{Wi}-\mathrm{Fi}$, temperature sensor, moisture sensor humidity senor, motors used along with the coolers and the sliding window is given below in Fig.7

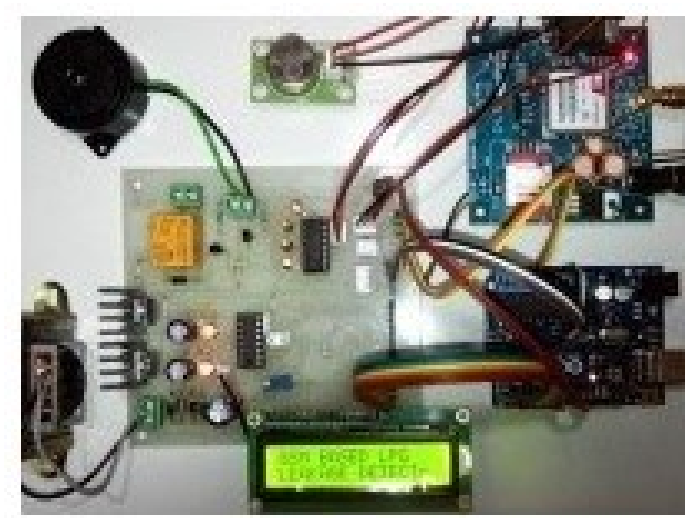

ISSN: 2582-418X (online)

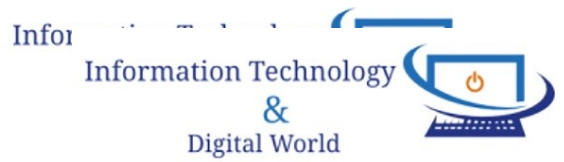


Journal of Information Technology and Digital World (2019)

Vol.01/ No. 01

Pages: $38-47$

https://www.irojournals.com/itdw/

DOI: https://doi.org/10.36548/jitdw.2019.1.005

Fig .7 Hardware Setup

The fig. 8 below is the snapshot of the result visualized by employing the automated greenhouse system that is equipped with the coolers, sliding windows and the sensors. The fig.9 below is the SMS Alerts transmitted to the user on regular intervals.

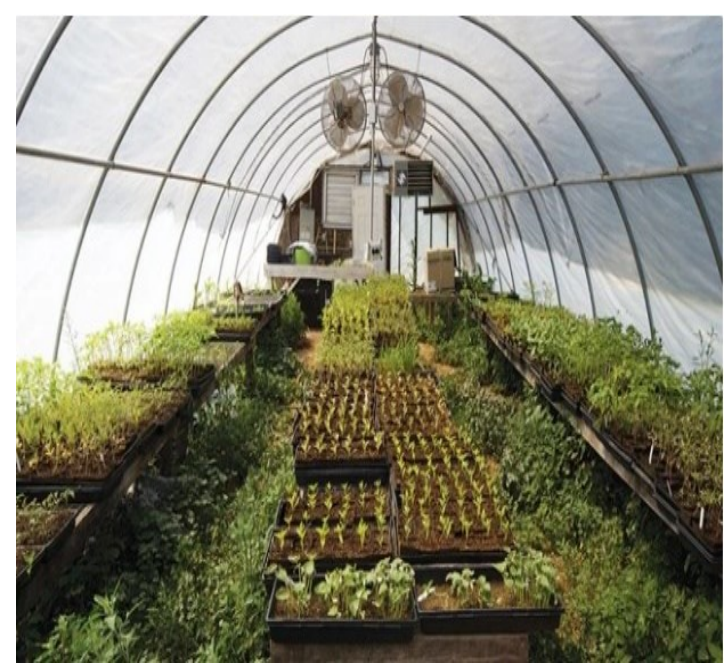

Fig .8 Results Acquired

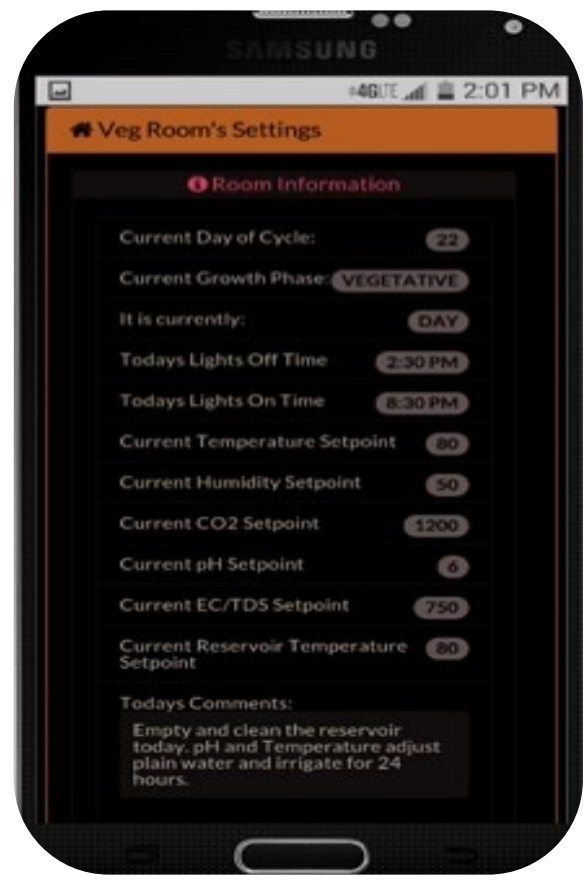

Fig.9 SMS Alert

\section{CONCLUSION}

The automated system for the green house management (control and monitoring) in the paper is done by employing the sensors of temperature, moisture, humidity and light for the monitoring of the environmental changes and the Netduino to regulate the driver circuits to maintain the normal climatic conditions within the green house. The remote monitoring and the control of the green house is enabled in the system using the IOT platform and the cloud services that store the information and sends the regular SMS alters to the farmer about the room conditions. The Wi-Fi connectivity in built in the Netduino enables an easy information transfer to the cloud. The Google Cloud IOT core used in the system enables the conveyance of the information gathered about the green house to the farmers. The 
Journal of Information Technology and Digital World (2019)

Vol.01/ No. 01

Pages: $38-47$

https://www.irojournals.com/itdw/

DOI: https://doi.org/10.36548/jitdw.2019.1.005

proffered system using the Netduino ensures production increase and a stress reduction for the farmers providing a capable automated system for green house management with a SMS alters to the users.

\section{References}

[1] Sreekantha, D. K., and A. M. Kavya. "Agricultural crop monitoring using IOT-a study." In 2017 11th International Conference on Intelligent Systems and Control (ISCO), pp. 134-139. IEEE, 2017.

[2] Suma, N., Sandra Rhea Samson, S. Saranya, G. Shanmugapriya, and R. Subhashri. "IOT based smart agriculture monitoring system." International Journal on Recent and Innovation Trends in computing and communication 5, no. 2 (2017): 177-181.

[3] Yoon, Chiyurl, Miyoung Huh, Shin-Gak Kang, Juyoung Park, and Changkyu Lee. "Implement smart farm with IoT technology." In 2018 20th International Conference on Advanced Communication Technology (ICACT), pp. 749752. IEEE, 2018.

[4] Vatari, Sheetal, Aarti Bakshi, and Tanvi Thakur. "Green house by using IOT and cloud computing." In 2016 IEEE International Conference on Recent Trends in Electronics, Information \& Communication Technology (RTEICT), pp. 246-250. IEEE, 2016.

[5] Linlin, Qin, Lu Linjian, Shi Chun, Wu Gang, and Wang Yunlong. "Implementation of IOT-based greenhouse intelligent monitoring system." Transactions of the Chinese Society for Agricultural Machinery 46, no. 3 (2015): 261267.

[6] Vimal, P. V., and K. S. Shivaprakasha. "IOT based greenhouse environment monitoring and controlling system using Arduino platform." In 2017 International Conference on Intelligent Computing, Instrumentation and Control Technologies (ICICICT), pp. 1514-1519. IEEE, 2017.

[7] Ferrández-Pastor, Francisco, Juan García-Chamizo, Mario Nieto-Hidalgo, Jerónimo Mora-Pascual, and José MoraMartínez. "Developing ubiquitous sensor network platform using internet of things: Application in precision agriculture." Sensors 16, no. 7 (2016): 1141.

[8] Zhao, Ji-chun, Jun-feng Zhang, Yu Feng, and Jian-xin Guo. "The study and application of the IOT technology in agriculture." In 2010 3rd International Conference on Computer Science and Information Technology, vol. 2, pp. 462465. IEEE, 2010.

[9] Muthupavithran, S., S. Akash, and P. Ranjithkumar. "Greenhouse monitering using internet of things." International Journal of Innovative Research in Computer Science and Engineering 2, no. 3 (2016).

[10] Mekala, Mahammad Shareef, and P. Viswanathan. "A Survey: Smart agriculture IoT with cloud computing." In 2017 international conference on microelectronic devices, circuits and systems (ICMDCS), pp. 1-7. IEEE, 2017. 
Journal of Information Technology and Digital World (2019)

Vol.01/ No. 01

Pages: $38-47$

https://www.irojournals.com/itdw/

DOI: https://doi.org/10.36548/jitdw.2019.1.005

[11] Shukla, Ami J., Mr Viraj Panchal, and Mr Sahil Patel. "Intelligent Greenhouse Design based on Internet of Things (IoT)." International Journal of Emerging Trends in Electrical and Electronics 11, no. 2 (2015): 78-86.

[12] Talavera, Jesús Martín, Luis Eduardo Tobón, Jairo Alejandro Gómez, María Alejandra Culman, Juan Manuel Aranda, Diana Teresa Parra, Luis Alfredo Quiroz, Adolfo Hoyos, and Luis Ernesto Garreta. "Review of IoT applications in agro-industrial and environmental fields." Computers and Electronics in Agriculture 142 (2017): 283297. 